7. Child Lang. 43 (2016), 8I I-842. (C) Cambridge University Press 2015

This is an Open Access article, distributed under the terms of the Creative Commons

Attribution licence (http://creativecommons.org/licenses/by/4.o/), which permits unrestricted re-use, distribution, and reproduction in any medium, provided the original work is properly cited.

doi:10.1017/So30500091 5000288

\title{
Converging and competing cues in the acquisition of syntactic structures: the conjoined agent intransitive
}

\author{
CLAIRE NOBLE \\ University of Liverpool
}

\author{
AND \\ FARIA IQBAL, ELENA LIEVEN AND \\ ANNA THEAKSTON* \\ University of Manchester
}

(Received 2 May 2014-Revised 30 Fanuary 2015-Accepted 20 May 2015-

First published online Io Fuly 20I5)

\section{ABSTRACT}

In two studies we use a pointing task to explore developmentally the nature of the knowledge that underlies three- and four-year-old children's ability to assign meaning to the intransitive structure. The results suggest that early in development children are sensitive to a first-noun-as-causal-agent cue and animacy cues when interpreting conjoined agent intransitives. The same children, however, do not appear to rely exclusively on the number of nouns as a cue to structure meaning. The pattern of results indicates that children are processing a number of cues when inferring the meaning of the conjoined agent intransitive. These cues appear to be in competition with each other and the cue that receives the most activation is used to infer the meaning of the construction. Critically, these studies suggest that children's knowledge of syntactic structures

[*] We would like to thank all the nurseries and children who took part in the research reported here. Thanks are also due to Caroline Rowland and Franklin Chang for helpful comments. This research was funded by the Max Planck Institute for Evolutionary Anthropology, Leipzig. Elena Lieven is a professor, and Anna Theakston is a senior lecturer in the ESRC International Centre for Language and Communicative Development (LuCiD) at The University of Manchester. The support of the Economic and Social Research Council [ES/Loo8955/I] is gratefully acknowledged. Address for correspondence: Anna Theakston, School of Psychological Sciences, University of Manchester. e-mail: anna.theakston@manchester.ac.uk 
forms a network of organization, such that knowledge of one structure can impact on interpretation of other structures.

\section{INTRODUCTION}

Previous research concerning the acquisition of argument structure has tended to focus on the age at which children can correctly interpret syntactic constructions (e.g., Gertner, Fisher, \& Eisengart, 2006; Naigles, I 990). Consequently, a key trend in the literature has been to demonstrate that children have some knowledge of syntactic structure, allowing them to correctly assign meaning to particular constructions at above-chance levels, at increasingly younger ages. More recently though, attention has turned to the particular cues that children might use to interpret sentences (e.g., Dittmar, Abbot-Smith, Lieven, \& Tomasello, 2008, following on from MacWhinney, Pleh, \& Bates, i985) in an attempt to understand how children assign meaning, and how this changes developmentally. To date, most of this work has focused on a single construction, the active transitive, which limits our understanding of how cues might operate across different sentence types. In this paper, we present two studies exploring which cues English-speaking children use to infer meaning in the conjoined agent intransitive, and how sensitivity to these cues changes over the course of development. Our goal is to gain an understanding of why some sentence constructions are more difficult to comprehend than others, and to provide insights into how cues involved in the acquisition of multiple construction types interact to underlie both correct interpretations and misinterpretations.

One framework that advocates the importance of cues in sentence comprehension is the Competition Model (MacWhinney et al., i985). When comprehending a sentence in a given language, the Competition Model predicts that the listener makes use of all of the cues present in an utterance (e.g., word order, animacy, case, construction meaning). Each of the cues has a relative weight, which is calculated in terms of how frequent the cue is when it is needed (cue availability) and how consistently it is mapped onto a particular form when it is present (cue reliability). For example, if a cue is always available in the input then it will have high availability; similarly, if, when a cue is present, it always indicates the same outcome, it has high reliability. Cue validity is the product of reliability and availability and the cue that has the highest overall validity is used to infer the meaning of the utterance. When cues individually indicate different possible meanings for a particular sentence, then the cue or perhaps coalition of cues which receives the most activation will be used to infer the meaning of the construction (e.g., Bates \& MacWhinney, I 987 ). Within this approach, if a sentence is interpreted incorrectly, this is 
likely to reflect reliance on a cue or cues that ordinarily would not win out for a particular construction type. This could reflect processing demands in adults, or differences in the underlying linguistic representations available in the developing child compared to an adult speaker. Relative activation levels may vary between children and adults as a function of relative frequencies in the input and the nature of existing sentence representations at any given developmental point, as well as the linguistic task at hand.

In terms of language acquisition, the competition model makes predictions about the order in which learners will acquire grammatical devices in different languages. If a cue is high in availability yet low in reliability it will be learned early but will be vulnerable to overgeneralizations due to low reliability. Cues that are less available but high in reliability may be weaker initially but will slowly strengthen, eventually winning out over the more frequent but unreliable cues. In theory at least, this appears fairly straightforward. In practice, however, the question of how the various cue weights should be calculated is extremely complex, presenting a serious challenge to researchers wishing to understand how these cues might interact during language acquisition. Specifically, the issue concerns what should be counted, and when, with some researchers choosing to focus on the target construction in isolation, while others argue for a broader language-wide approach (e.g., see Ambridge, Kidd, Rowland, \& Theakston, 20I 5, and Dittmar et al., 2008; and for discussions of calculating frequency: Chang, Dell, \& Bock, 2006, for a model of construction-general and construction-specific frequency effects).

Previous research which has focused on the comprehension of simple transitive sentences has investigated the role of cues such as word order, animacy, and case marking. These studies have demonstrated crosslinguistically that sentences with converging cues are easier to interpret than those with conflicting cues, and that children appear to be adjusting the relative weights of these cues as their language experience increases over the course of development (e.g., Dittmar et al., 2008, for German; Chan, Lieven, \& Tomasello, 2009, for Cantonese, German, and English; Ibbotson, Theakston, Lieven, \& Tomasello, 20I I, for English; Candan, Küntay, Yeh, Cheung, Wagner, \& Naigles, 20ı2, for English, Turkish, and Mandarin; O’Shannessy, 20го, for two Walpiri languages; Krajewski \& Lieven, 20I4, for Polish; Lemetyinen, Theakston, \& Lieven, in prep, for Finnish). These studies all indicate that while children can interpret the transitive early in development, this ability varies as a function of the cues present in a given transitive sentence. On this basis it is possible that some sentence constructions are more difficult to comprehend than others early in development due to the role of cues to meaning across these constructions. 
In English a clear pattern has emerged in the literature, indicating that children are able to use word order to comprehend the transitive earlier than the conjoined agent intransitive (Arunachalam \& Waxman, 2010; Hirsh-Pasek, Golinkoff, \& Naigles, r 996; Kidd, Bavin, \& Rhodes, 200ı; Naigles \& Kako, ı 993; Noble, Rowland, \& Pine, 20ı i; Yuan \& Fisher, 2009, though see Naigles, I990, and Kidd, Bavin, \& Rhodes, 200 I). For example, Noble et al. (20I I) used a within-subjects design to investigate whether children (aged 2;3, 3;4, and 4;3) have verb general knowledge of both the transitive and conjoined agent intransitive constructions early in development. The findings indicated that children aged 2;3 were able to correctly associate the transitive structure with a causal scene, but the same children were unable to associate the conjoined agent intransitive with a non-causal scene. In this study, older children aged 3;4 were able to successfully interpret the conjoined agent intransitive.

The question is, then, why is the transitive easier to interpret than the conjoined agent intransitive? If this asymmetry in performance reflects an asymmetry in knowledge, then the question facing the field is what kind of syntactic knowledge underlies the early ability to infer the meaning of the transitive but the later acquisition of the conjoined agent intransitive. In the present paper we consider the possibility that the later acquisition of the conjoined agent intransitive is related to the cues to meaning present in the two constructions.

Previous research has identified two specific cues (also known as processing biases/structure mapping biases), which preferentially indicate the correct interpretation of the transitive, but would mislead children if applied in the interpretation of conjoined agent intransitives. Reliance on these cues could thus account for the apparent asynchrony in the acquisition of transitive and conjoined agent intransitive constructions.

First, it has been suggested that, early in development, children are biased to assume that the first named noun in a sentence is a causal agent (first-noun-as-causal-agent cue; cf. Bever, I970; Slobin, I966). In English, reliance on this cue would allow children to correctly interpret many structures in which the first named noun is the causal agent, but could also lead to incorrect interpretation of structures in which the first named noun is not the causal agent, such as the non-causal conjoined agent intransitive.

There is evidence to suggest that English-learning children may assume that the first named noun in an utterance corresponds to the causal agent role regardless of the syntactic structure. For example, Bever (r970) tested children's comprehension of both simple active and passive sentences and found that children aged 2 ; 0 to 3 ; 0 acted out $95 \%$ of active sentences correctly compared to only 50\% of the passives. Maratsos (I974) replicated these findings and showed that children did not reliably comprehend

$$
8 \text { I } 4
$$


passive sentences until four years of age. Both suggested that the pattern of results was due to the overuse of the statistical generalization that noun-verb-noun sentences follow an agent-verb-patient order. There is also evidence that adults may default to assuming that the first noun is the causal agent under certain processing conditions. Ferreira (2003) reported that undergraduate students frequently and systematically misinterpreted passive (e.g., The boy was kicked by the girl) and object cleft sentences (e.g., It was the boy the girl kicked). The predominant error was to incorrectly name the first noun as the agent and the second noun as the patient.

In a recent study, Gertner and Fisher (2012) reported that a first-nounas-causal-agent cue does seem to influence comprehension of conjoined agent intransitives in children aged $\mathbf{1} ; 9$. Using a preferential looking method, children were presented with a causal scene (e.g., a boy swivelling a girl in a chair) and a non-causal scene (e.g., a boy and a girl twirling ribbons) accompanied by either a transitive (NVN) or a conjoined agent intransitive (NNV) sentence. The order of the nouns in the conjoined agent intransitive was manipulated to create two conjoined agent intransitive conditions. Children in the PATIENT-FIRsT condition heard conjoined agent intransitives in which the first noun was not the agent in the non-matching causal scene (e.g., the girl and the boy are gorping). In the AGENT-FIRST condition, children heard conjoined agent intransitives in which the first noun was the agent in the non-matching causal scene (e.g., the boy and the girl are gorping). The results showed that children aged I;9 correctly associated the transitive with the causal scene and the patient-first conjoined agent intransitive with the non-causal scene. However, children in the agent-first condition did not correctly associate the conjoined agent intransitive with the non-causal scene, suggesting an influence of a first-noun-as-causal-agent cue. Thus, it appears that reliance on this cue may account for why comprehension of the transitive emerges before comprehension of the conjoined agent intransitive.

A second cue that may preferentially favour interpretation of the transitive over the conjoined agent intransitive construction is the number of nouns in an utterance. It has been suggested that children are biased to treat each noun as having a distinct semantic role (Fisher, I994, I 996, 2002; see Lidz, Gleitman, \& Gleitman, 2003, for a similar account). Reliance on this cue would allow children to correctly interpret sentences in which the number of nouns and semantic roles are aligned (e.g., the transitive). However, it would also lead to incorrect interpretation of sentences in which the number of nouns and semantic roles are not aligned, such as the conjoined agent intransitive where two nouns (e.g. the bunny and the duck in the duck and the bunny are eating) map onto a single semantic role. In this case, given a choice of a causal and non-causal scene accompanied by a conjoined agent 
intransitive, children would be predicted to select the causal scene including both an agent and patient as a semantic match. There is evidence that young children can use the number of nouns in a sentence as an indicator of its semantic predicate argument structure (Fisher, I 994, I996, 2002).

For example, Fisher (2002) found that children as young as 28 months used the number of nouns in a sentence to infer the meanings of novel verbs. Children were presented with a caused motion scene (e.g., Participant A pulls B backwards along a slippery surface by pulling on B's backpack) accompanied by either a one-noun sentence (she pilks over there) or a two-noun sentence (e.g., she pilks her over there). Then the children were asked either, "Which one verb-ed the other? Point!" or "Which one verb-ed? Point!" When the accompanying audio and question included two noun phrases, the children were more likely to point to the causal agent than when the accompanying audio and question included only one noun phrase. This was taken as evidence that children are sensitive to the number of nouns within a construction and can use this property to constrain the meanings of novel verbs. Based on this evidence, it is possible that the presence of two nouns in the conjoined agent intransitive could lead children to associate the sentence with a causal scene.

Aside from these cues, there are a number of additional cues which could influence comprehension of the conjoined agent intransitive. First, knowledge of the form-function mappings for early learned constructions may impact on sentence interpretation for less frequent or later learned constructions. Cameron-Faulkner, Lieven, and Tomasello (2003) reported that the simple transitive construction is more frequent in the input to children than the simple intransitive ( $10 \%$ vs. $3 \%$ ), and the conjoined agent intransitive is extremely infrequent and did not appear in the sample of intransitives (Cameron-Faulkner, personal communication). This means that, based purely on opportunities for learning, children are likely to have greater knowledge of the form-function mappings associated with the transitive construction than the intransitive construction. More specifically, while they are likely to assign a causal meaning to NVN sentences, the meaning associated with NNV sentences is likely to be less well specified.

Previous research examining one child's early language production data has demonstrated that knowledge of early learned constructions can both support and hinder the acquisition of later learned constructions as a function of the degree of formal and semantic overlap (Abbot-Smith \& Behrens, 2006). In comprehension, then, it seems possible that activation of the form-function mappings associated with early learned constructions could serve to influence children's performance when interpreting less frequent, later learned constructions. More specifically, if the prototypical form-function mappings associated with the early learned transitive (i.e., an animate agent acting on an inanimate patient) are activated by certain 
aspects of a conjoined intransitive sentence, this could either support or hinder correct sentence interpretation. On the one hand, the shared activation of a two-participant scene may lead children to assign the sentence a causal (transitive) meaning, leading to misinterpretation. On the other hand, a two-participant scene, in particular one in which the animacy and ordering of the participants maps onto the prototypical transitive structure, could activate the NVN structure typically associated with two-participant scenes. This could help children to recognize the mismatch between the activated/expected NVN structure and the heard NNV structure, leading to a correct non-causal interpretation.

Second, as alluded to above, the animacy of the participants may provide another cue to meaning. In the English transitive construction, the majority of sentences children both hear and produce contain an animate subject and inanimate object from the earliest stages of development $(88 \cdot 9 \%$ in the input, compared to just $6 \cdot \mathrm{I} \%$ animate-animate, and $0 \cdot 19 \%$ inanimate-animate; Theakston, Maslen, Lieven, \& Tomasello, 2012). In contrast, intransitives, typically associated with non-causal scenes, contain a higher proportion of inanimate subject arguments than simple transitive sentences, a pattern that holds cross-linguistically (e.g., Clancy, 2003; DuBois I987). Thus, the animacy configuration of the nouns may provide a strong cue to sentence interpretation.

In sum, sensitivity to a range of cues could lead to the correct interpretation of transitive argument structure earlier than conjoined agent intransitive structure, and thus may account for the asynchrony in acquisition of the two structures. Table I summarizes the potential cues children might use to interpret the conjoined agent intransitive. However, when and how children correctly set weights of cues and when they overcome reliance on particular cues remains unclear. In Study I, we investigated whether children aged three and four years are sensitive to a first-noun-as-causal-agent cue and a number of nouns cue. In Study 2, we expanded the range of surface cues available for the assignment of meaning to the conjoined agent intransitive structure by investigating whether the animacy of the two nouns affects children's interpretation of the structure. Here, the aim was to cast light on which of the possible cues children pay attention to, and thus to begin to understand more about how children's knowledge of the conjoined agent intransitive construction relates to their existing knowledge of the simple transitive.

\section{STUDY I}

Study I was similar in nature to Gertner and Fisher (2012) described earlier, in that we tested the effects of having the first noun in a conjoined agent intransitive either match or mismatch the causal agent in a distractor causal 
TABLE I. Summary of the cues children may use to interpret conjoined agent intransitives in Studies I and 2, and performance in each age group

\begin{tabular}{|c|c|c|c|c|c|c|c|}
\hline \multirow{2}{*}{ Sentence types } & \multicolumn{5}{|c|}{ Cues to interpretation of conjoined agent intransitives } & \multicolumn{2}{|c|}{ Performance } \\
\hline & $\begin{array}{l}\text { Structural } \\
\text { cue }\end{array}$ & $\begin{array}{l}\text { Does first noun } \\
\text { correspond to } \\
\text { causal agent? }\end{array}$ & $\begin{array}{l}\text { Do the number } \\
\text { of nouns and } \\
\text { semantic roles } \\
\text { match? }\end{array}$ & $\begin{array}{l}\text { Does animacy of } \\
\text { preverbal noun(s) } \\
\text { favour causal or } \\
\text { non-causal } \\
\text { meaning? }\end{array}$ & $\begin{array}{l}\text { Is the animacy pattern } \\
\text { compatible with high-, } \\
\text { low-, or very } \\
\text { low-frequency } \\
\text { transitive? }\end{array}$ & $3 \mathrm{yrs}$ & $4 \mathrm{yrs}$ \\
\hline $\begin{array}{l}\text { Conjoined agent intransitive } \\
\text { with agent conflict (AN-AN) } \\
\text { "The bunny and the duck are } \\
\text { glorping" The bunny is the } \\
\text { agent in the causal scene }\end{array}$ & Non-causal & $\checkmark$ & $x$ & Causal & $\checkmark$ low & $x$ & $\checkmark$ \\
\hline $\begin{array}{l}\text { Conjoined agent intransitive } \\
\text { with no-Agent conflict } \\
\text { (AN-AN) "The duck and the } \\
\text { bunny are glorping" The duck } \\
\text { is the patient in the causal } \\
\text { scene }\end{array}$ & Non-causal & $x$ & $x$ & Causal & $\checkmark$ low & $\checkmark$ & $\checkmark$ \\
\hline $\begin{array}{l}\text { Simple intransitive "The } \\
\text { animals are glorping" }\end{array}$ & Non-causal & $\checkmark$ & $\checkmark$ & Causal & $x$ & $x$ & $x$ \\
\hline $\begin{array}{l}\text { Conjoined agent intransitive } \\
\text { AN-AN"The bunny and the } \\
\text { duck are glorping”The bunny is } \\
\text { the agent in the causal scene }\end{array}$ & Non-causal & $\checkmark$ & $x$ & Causal & $\checkmark$ low & $x$ & N/A \\
\hline $\begin{array}{l}\text { Conjoined agent intransitive } \\
\text { AN-IN “The bunny and the ball } \\
\text { are glorping" The bunny is the } \\
\text { agent in the causal scene }\end{array}$ & Non-causal & $\checkmark$ & $x$ & Causal & $\checkmark$ high & $\checkmark$ & N/A \\
\hline $\begin{array}{l}\text { Conjoined agent intransitive } \\
\text { IN-AN "The ball and the duck } \\
\text { are glorping" The ball is the } \\
\text { agent in the causal scene }\end{array}$ & Non-causal & $\checkmark$ & $x$ & Non-causal & $\checkmark$ very low & $\checkmark$ & N/A \\
\hline
\end{tabular}


scene, but had three critical differences. First, the children were older to allow us to investigate the influence of these cues developmentally. Second, we used a forced choice pointing task, as it is less ambiguous to analyze and more suitable for our age group than a preferential looking task. Third, we also included test items to investigate whether children infer the meaning of a structure on the basis of the number of nouns in the sentence.

We predicted that the conflict between the first-noun-as-causal-agent cue and the structural meaning of the conjoined agent intransitive would reduce the accuracy of the children's interpretation of the agent-conflict sentences, but that performance on no-agent-conflict sentences would be more accurate because, in the absence of the conflict, children will rely on other cues to meaning. We predicted that if children are inferring the meaning of a structure by assigning a distinct semantic role to each noun, they should associate a simple intransitive (with one noun) with the non-causal synchronous action, which has only one semantic role, the conjoined agent.

\section{METHOD}

\section{Participants}

Forty-eight three-year-olds (mean age $=3 ; 4 ; S D=3$ months; range: $2 ; \mathrm{I}$ I $-3 ;$ Io), forty-eight four-year-olds (mean age $=4 ; 3 ; S D=3$ months; range: $3 ; \mathrm{I} \mathrm{I}-4 ; 8$ ) and eleven adults (mean age $=22$ years; $S D=4$ years; range: $18-30$ years) participated in a language comprehension task using the forced choice pointing method. All were native speakers of British English who had no language difficulties. A further six participants were excluded due to experimenter error (I), failure to pass the screening trials (2), and a side bias (3).

\section{Design}

The task employed a $2 \times 3$ mixed design with two independent variables: Age - between subjects with two levels (three-year-olds vs. four-year-olds), and sentence type-within subjects with three levels (agent conflict, no-agent conflict, simple intransitive). In the test trials the non-causal synchronous action scene was always the matching scene and the dependent variable was the proportion of points to the matching noncausal scene.

\section{Counterbalancing}

All four sentences of a given type (agent conflict or no-agent conflict or simple intransitive) were presented together in a single block. The order of the trials within each block was randomized. Across children each movie appeared with no-agent-conflict audio, agent-conflict audio and 
simple intransitive audio. The order of the testing blocks was fully counterbalanced and the target side was balanced within each sentence type.

\section{Materials}

Visual stimuli. The visual stimuli were created in Anime Studio Pro and exported as movies to QuickTime. Each movie consisted of cartoon animations of ducks, rabbits, teddies, and frogs performing novel actions. The movies were presented on a laptop and showed two animations side by side, one of which was the target scene. The movies lasted I 2 seconds to allow us to present a familiarization sentence and then to show the children the action scenes twice. In all test trials one scene showed a causal action (e.g., a duck acting on a rabbit) and the other scene showed a noncausal scene (e.g., both the duck and the rabbit performing the same actions independently). (See 'Appendix' for details of the twelve novel action pairs and associated novel verbs.)

Audio stimuli. The sentences were delivered by a speaking rabbit called Flopsy (this method has been successfully used in previous studies; cf. Rowland \& Noble, 20II; Noble et al., 20II). A native female British English speaker recorded the audio stimuli, which were edited in Audacity and exported into the Quick'Time movies. To create the effect of a rabbit speaking, a toy rabbit with speakers hidden inside was used to play the audio stimuli. Twelve novel verbs were used: dax, glorp, wug, pilk, jemm, rick, filp, rax, blick, krad, meek, grad. As the actions in the two scenes were different, novel verbs were used to ensure that the children could not locate the correct scene on the basis of knowledge of the verb alone. The task was not a verb learning task. The novel verb was never presented in isolation and the meaning of the novel verb was never taught; it was always embedded in a relevant syntactic context. The child needed to use the meaning associated with the syntax to locate the matching scene.

In the agent-conflict test trials, children heard conjoined agent intransitive sentences in which the first named noun (e.g., the bunny in The bunny and the duck are glorping) was also the causal agent in the causal scene. In the no-agent-conflict sentences, children heard conjoined agent intransitive sentences in which the first named noun (e.g., the duck in The duck and the bunny are glorping) was the patient in the causal scene. In the simple intransitive test trials, children heard intransitive sentences in which the number of nouns and semantic roles was aligned through the use of one plural noun (e.g., the animals in The animals are glorping). Previous research has indicated that children begin to correctly produce plural morphemes from i; Io (Barner, Thalwitz, Wood, \& Carey, 2007; Clark \& Nikitina, 2009) and show comprehension of plural morphology from 2;0 (Kouider, Halberda, Wood, \& Carey, 2006; Wood, Kouider, \& Carey, 
2009). Therefore, we were confident that the plural morphology used would not pose a problem for even the youngest age group.

In each test trial the novel verb was presented three times. The test trial began with a familiarization phase in which the children heard an intransitive in the future 'going to' tense in the absence of any visual stimuli. (e.g., Look! The bunny and the duck are gonna glorp). The visual stimuli then appeared and the children then heard the test sentence in the present tense (e.g., The bunny and the duck are glorping). Finally, the action scene was repeated and the test sentence was repeated in the present tense with the addition of the pointing command (e.g., Point to where the bunny and the duck are glorping).

Visual preferences. An additional group of three-year-olds and a group of four-year-olds took part in a screening test to determine whether they exhibited a preference for either the causal or non-causal synchronous action visual scenes in the absence of informative linguistic input, i.e., the syntax to be presented in the test condition. Each child followed exactly the same procedure as children in the main test condition (as outlined below) and saw exactly the same visual stimuli. The only difference was that, on the test items, the novel verb was presented in isolation (e.g., Look! Glorping!) rather than in a conjoined agent intransitive. A one-sample $t$-test was run for each age group with chance set at 50\% (6/12 trials) and mean rate of pointing to the non-causal scene (i.e., the matching scene in the test condition) as the dependent variable. There was a small but significant departure from $50 \%$ for both the three-year-olds $\left(M=5 \cdot 29, S D={ }_{1} \cdot 52\right.$, $t(23)=-2 \cdot 29, p=\cdot 03, d=0.95)$ and the four-year-olds $(M=5 \cdot 38, S D=\mathrm{I} \cdot 35$, $t(23)=-2 \cdot 28, p=.03, d=0.95)$. Given that both age groups preferred the causal scene in the absence of directive audio, we can be sure that any above-chance performance in the test sentences will not simply reflect a visual preference for the non-causal scene.

\section{Procedure}

Testing took place in a child language laboratory or in a quiet room in the children's nursery. During all trials the experimenter sat alongside the child. All children were given the option of being accompanied by a familiar adult who sat behind the child and experimenter and interacted minimally with the child. To ensure that the child could not locate the target scene by using the experimenter's eye-gaze, once the trial had started the experimenter focused their gaze on the child, not the scenes. The order of the trials was: Character identification $>$ Screening trials $>$ Real verb practice trials $>$ Test trials. The visual and audio stimuli presented in the character identification, screening, and training trials have been used successfully in a previous study (Noble et al., 20I I) and are 
described in detail below. To confirm that adult speakers would accept the non-causal scenes in the test stimuli as an appropriate match for the three intransitive sentence types a sample of adults $(N=$ I I $)$ was also tested. The same procedure was used for adults and children.

Character identification. The character identification phase was designed to familiarize the children with the animals they would see in the test. The child was shown a still picture of the four characters (duck, teddy, frog, and rabbit) and the investigator told the child they were going to play a pointing game. The experimenter referred to the collection of characters as animals (e.g., "Can you see all the animals?") The child was then asked to point to each one in turn (e.g., "Point to the duck"). All children correctly identified all characters.

Screening. Each child then completed three screening trials. The investigator explained to the child that there were now two animations to watch but that Flopsy the rabbit would only talk about one of the pictures. The child was told $\mathrm{s} /$ he must watch the pictures and listen to what Flopsy said and then point to the picture that Flopsy talked about. In each trial an animal performed an action in one scene and the same animal stood still in the other scene. There was only one animal in each scene. The accompanying audio was a simple intransitive sentence. For example: the left-hand image showed a teddy standing still and the right-hand animation showed the teddy bending down. The accompanying audio was "The teddy is klimping. Point to where the teddy is klimping".

If the child did not point during the movie, the investigator prompted her/ him by asking "Which picture?" or "Can you point to the picture Flopsy was talking about?" If the child still did not point, the movie was repeated. After repeating the movie, if the child still did not point, the investigator asked the child to stick a sticker on the correct picture. The movie was run again and the child instructed to stick the sticker directly on the computer screen onto the picture which Flopsy talked about. After each trial the sticker was removed and given back to the child before the next trial began. If the child pointed to the incorrect picture in the screening trials $s /$ he was praised for pointing but shown which scene was actually the matching scene and given another opportunity to see the movie.

The child's first point (prior to any feedback) was always taken as his/her response unless s/he changed his/her mind and expressed this clearly. If the child's point was ambiguous (e.g., s/he pointed to both animations or pointed to the centre of the two animations), the child was reminded to point to only one of the pictures and the trial was re-run. This procedure was repeated for all three screening trials.

As the test trials of the study required the child to associate an intransitive structure with an action scene it was necessary to exclude children who showed a systematic bias to associate the intransitive with a stationary 
scene in the screening trials, presumably by analogy to intransitives such as the bear is sitting ( 2 children). To pass the screening trials the children had to point to the action scene in at least two of the three screening trials.

Real verb practice trials. Each child then completed two real verb practice trials. These trials were included to give the child further practice on the task before the test trials began. In these trials there were two animals present in each animation, and to avoid further training on intransitive sentences, transitive sentences were used. Each movie showed an animal performing an action in one scene and the same animal performing a different action in the other scene. For example, the left-hand animation showed a frog washing a teddy and the right-hand animation showed a frog hugging a teddy. The accompanying audio was "The frog is washing the teddy! Point to where the frog is washing the teddy!" As the audio contained a real verb and the agent was the same animal in both scenes, these trials were a test of the child's real verb knowledge. If the child pointed to the incorrect picture in the real verb trials $s /$ he was praised for pointing but shown which scene was actually the matching scene and given another opportunity to see the movie.

Test trials. The test trials followed the real verb practice trials. Each participant completed twelve novel verb test trials, a block of four agent-conflict conjoined agent intransitive sentences, a block of four no-agent-conflict conjoined agent intransitive sentences, and a block of four simple intransitives. Previous studies using a pointing methodology have successfully presented more than twelve test trials to similarly aged children (cf. Ibbotson et al., 20I I). The procedure for the test trials was identical to the procedure for the real verb practice trials except that the child was NOT corrected if $\mathrm{s} /$ he pointed to the incorrect picture. The child was instead praised for pointing regardless of whether $s /$ he pointed to the correct picture. (See 'Appendix' for an example of the stimuli and sequence of events.)

\section{Coding}

The trials were coded in real time during the experimental session. The child's first unambiguous point was always taken as his/her response unless s/he changed his/her mind and expressed this clearly. The investigator recorded whether the child pointed to the non-causal or causal scene in all trials. An additional blind coder coded $15 \%$ of the children tested and inter-rater reliability was $100 \%$.

\section{RESULTS}

The first analysis checked whether adults associated the three intransitive sentence types with the non-causal scene. Table 2 shows the mean number of points to the non-causal scene for each sentence type. It is clear that the 
TA В LE 2. Mean number of points to non-causal scene (SD) for each intransitive sentence type for three-year-olds, four-year-olds, and adults

\begin{tabular}{llll}
\hline & $3 ; 4$ & $4 ; 2$ & Adults \\
\hline Agent conflict intransitive (4 trials) & $2 \cdot \mathrm{I} 3(\mathrm{I} \cdot \mathrm{I} 5)$ & $2 \cdot 63(0.92)$ & $3 \cdot 45(\mathrm{I} \cdot 2 \mathrm{I})$ \\
No agent conflict intransitive (4 trials) & $2 \cdot 50(0 \cdot 88)$ & $2 \cdot 38(0.7 \mathrm{I})$ & $3.55(0 \cdot 82)$ \\
Simple intransitive (4 trials) & $2 \cdot 08(0.97)$ & $\mathrm{I} \cdot 75(0.94)$ & $3.55(\mathrm{I} \cdot 2 \mathrm{I})$ \\
\hline
\end{tabular}

adults were close to ceiling on all three sentence types. A one-sample $t$-test was run for each sentence type, with the mean number of points to the non-causal scene as the dependent variable and chance set at $50 \%(2 / 4)$.

The results showed that adults pointed to the non-causal scene significantly more often than we would expect by chance for all three intransitive sentence types, no-agent-conflict sentences $(M=3.55, S D=$ $0.82, t(\mathrm{IO})=6.25, p=.00 \mathrm{I}, d=3.95)$, agent-conflict sentences $(M=3.45$, $S D=\mathrm{I} \cdot 2 \mathrm{I}, t(\mathrm{IO})=3.98, p=.003, d=2.52)$, and simple intransitives $(M=$ $3.55, S D=\mathrm{I} \cdot 2 \mathrm{I}, t(\mathrm{I0})=4.22, p=.002, d=2 \cdot 67)$. This confirms that, for the adults, the non-causal scene was an appropriate match for the linguistic audio.

The second analysis examined performance on the real verb practice trials in order to check that children in both age groups were able to complete the simple pointing task. The screening trials were not included in this analysis as failure to pass the screening trials was an exclusion criterion; therefore all children in the final sample were able to complete the screening trials. A one-sample $t$-test was run for the three-year-olds, with mean rate of pointing to the matching scene and chance set at I (50\% of 2 trials). The analysis confirmed that the children were pointing to the matching scene significantly more than would be expected by chance $(M=\mathrm{I} \cdot 7 \mathrm{I}, S D=$ $0.43, t(23)=7.47, p=.00 \mathrm{I}, d=3.12)$. A one-sample $t$-test was not run for the four-year-olds, as all children, in all trials, pointed to the matching scene. This indicates that children in both age groups understood the requirements of the task.

The third analysis investigated performance by both age groups on the three sentence types (agent conflict, no-agent conflict, and simple intransitive sentence). To allow comparison with the adult participants, Table 2 shows the mean rate of pointing to the non-causal scene for each sentence type for the three-year-olds and four-year-olds.

A two-way repeated-measures ANOVA was run with sentence type (agent conflict vs. no-agent conflict vs. simple intransitive) and age group (3-year-olds vs. 4-year-olds) as the independent variables, and mean rate of pointing to the non-causal scene as the dependent variable. There was a main effect of sentence type $(F(2,92)=4 \cdot 26, p=.02$, partial eta squared $=.09)$, and no main effect of age group $(F(\mathrm{r}, 46)=0.008, p=\cdot 93$, partial eta 
TAB LE 3. Number of children selecting the non-causal scene above chance, or at chance and below, for both age groups on the agent conflict test trials

\begin{tabular}{lccc}
\hline Age & Chance and below (o-2 trials) & Above chance (3 or 4 trials) & Total \\
\hline 3 & I6 & 8 & 24 \\
4 & 9 & I 5 & 24 \\
\hline
\end{tabular}

squared $=.00 \mathrm{I})$. There was a near significant interaction between sentence type and age group $\left(F\left(\mathrm{I}, 5_{2}\right)=\mathbf{2} \cdot 48, p=.089\right.$, partial eta squared $\left.=.05\right)$. Post-hoc comparisons investigating the main effect of sentence type showed that the children performed significantly worse on simple intransitive sentences $\left(M=\mathrm{I} \cdot 92, S E=\cdot \mathrm{I}_{3} 8\right)$ than on agent-conflict sentences $\left(M=2 \cdot 38, S E=\cdot_{1} \mathrm{I}_{1}, p=.024\right)$ and no-agent-conflict sentences ( $M=2 \cdot 44, S E=\cdot$ I $16, p=\cdot$ ० го). Collapsed across age groups, there was no significant difference in performance between agent-conflict and no-agentconflict sentences. However, the marginally significant interaction between sentence type and age suggests that there may be subtle differences in the children's performance in the two age groups.

To investigate the subtle interaction between sentence type and age further, a one-sample $t$-test was run for each sentence type for each age group, with the mean number of points to the non-causal scene as the dependent variable and chance set at 50\% (2/4 trials), with $p$ values adjusted using the Benjamini-Hochberg method for multiple comparisons. The results showed that the three-year-olds pointed to the non-causal scene significantly more than chance for the no-agent-conflict sentences $(M=2 \cdot 5 \circ, S D=0 \cdot 88$, $\left.t(23)=2 \cdot 77, p=\cdot 03, d=\mathrm{I}_{5} 50\right)$, but not for the agent-conflict sentences $(M=$ 2. I $\left.3, S D=\mathrm{I}_{1} \mathrm{I}_{5}, t(23)=0.53, p=.68, d=0.22\right)$, or the simple intransitives $(M=2.08, S D=0.97, t(23)=0.42, p=.68, d=0.18)$. The four-year-olds pointed to the non-causal scene significantly more than chance for the no-agent-conflict sentences $(M=2 \cdot 38, S D=0.7 \mathrm{I}, t(23)=2.58, p=.034$, $d=\mathrm{I} \cdot 08)$ and the agent-conflict sentences $(M=2 \cdot 63, S D=0.92, t(23)=3 \cdot 32$, $p=\cdot \mathrm{oI} 8, d=\mathrm{I} \cdot 38)$, but not for the simple intransitive sentences $(M=\mathrm{I} \cdot 75$, $S D=0.94, t(23)=-\mathrm{I} \cdot 30, p=\cdot 3$ I $5, d=-0.54)$.

Thus, only the four-year-olds interpreted agent-conflict trials significantly above chance. To determine whether this age difference was robust, we compared the number of children in the two age groups who assigned a non-causal meaning to at least three of the four agent-conflict trials. A chi-squared test revealed that there was a significant difference between the age groups in the number of children who associated the agent-conflict sentences with a non-causal scene, with more four-year-olds performing above chance in comparison to the three-year-olds $\left(X_{2}(\mathrm{I}, N=48)=4.0904\right.$, $p=\cdot 043$ ); see Table 3 . 
The aim of Study I was to investigate whether the later acquisition of the conjoined agent intransitive is related to the cues to meaning present in the structure. Specifically, we tested whether children aged three and four are sensitive to a first-noun-as-causal-agent cue and a number of nouns cue when interpreting the meaning of a conjoined agent intransitive.

Children aged 3;4 showed inconsistent evidence of verb general knowledge of the intransitive structure, which appears to be due to the influence of the first-noun-as-causal-agent cue. They did not associate a conjoined agent intransitive sentence with a non-causal scene when the first noun matched the agent in the causal scene. However, the same children did associate the conjoined agent intransitive with a non-causal scene when the first noun was not the agent in the causal scene (but instead referred to the patient). This pattern of results supports those of Gertner and Fisher (2012), who found that children aged I;9 associated a no-agent-conflict sentence with a non-causal scene but were unable to associate the agent-conflict sentence with a non-causal scene.

Taken together, the results suggest that the three-year-olds continue to be influenced by a first-noun-as-causal-agent cue but also appear to have some knowledge of sentence structure. If children solely attended to the first-noun-as-causal-agent cue, in the extreme we would expect them to select the causal scene a large majority of the time when exposed to agent-conflict conjoined intransitives. In fact, what we see is at-chance performance; the three-year-olds are just as likely to select the non-causal scene as they are to select the causal scene for the agent-conflict sentences. This suggests that the children have some awareness that the causal scene is not an IDEAL match for the conjoined agent intransitive structure, despite the possible mapping of first noun to causal agent. In contrast, for the no-agent-conflict sentences, where there was no conflict between the first-noun-as-causal-agent cue and the structure, they associated the structure with the non-causal scene.

This pattern of results could reflect some knowledge of the conjoined intransitive structure and its meaning, such that three-year-olds are inclined to interpret conjoined agent intransitives as referring to a non-causal event, unless the presence of a first named noun that corresponds to the causal agent in the alternative scene introduces some confusion. On the other hand, this pattern of performance could be related to the child's knowledge of the transitive structure that more typically accompanies a causal scene. When there is no first noun that matches the agent of the causal scene, this may reduce the level of compatibility between the sentence the children hear and the causal scene they see. By eliminating the causal scene as a possible match, children may then select 
the alternative non-causal scene instead. Of course, these possibilities are not mutually exclusive but, either way, the presence of the first-noun-as-causalagent cue appears to reduce the children's performance in the agent-conflict sentences, and indicates that children's knowledge of sentence structure and their ability to deal with conflicting cues are both continuing to develop.

Children in the older age group and adults associated the conjoined agent intransitive with the non-causal scene regardless of the order of the nouns in the conjoined noun phrase. These findings indicate that while older children and adults may still be sensitive to a first-noun-as-causal-agent cue, their knowledge of sentence structure is stronger and thus guides them to the non-causal scene. On the basis of experience they have determined that the conjoined agent intransitive is typically associated with a non-causal meaning, and is thus incompatible with an interpretation based on firstnoun-as-causal-agent cue. At the same time, they have learned that a causal scene is typically described using a transitive structure and is thus incompatible with the conjoined agent intransitive sentence they have heard. In contrast, the pattern of results from the younger children indicates they have not yet fully learned the form-function mappings for the transitive and conjoined intransitive structures, or have yet to learn that sentence structure is the most reliable cue to meaning. Until more experience is gained and the cue weights are set correctly they will continue to show inconsistent comprehension of the conjoined agent intransitive.

None of the children associated the simple intransitive structure (e.g., the animals are glorping) with the non-causal scene. More specifically, when the number of nouns and the number of semantic roles were aligned, children did not associate this structure with the non-causal scene. This is contrary to what would be expected from previous studies which have indicated that children use the number of nouns in a sentence as an indicator of its semantic predicate argument structure from as young as 2;4 (Fisher, I 994, I 996, 2002).

We should be clear that the stimuli used in the present study differ considerably to the stimuli used in previous studies investigating this cue, which may account for the children's performance on the task. For example, Fisher (2002) used a caused motion event scene containing two participants and presented audio which contained either a single noun (e.g., she pilks over there) or two nouns (e.g., she pilks her over there). The task for these children was to locate an element in the scene when asked either "Which one (verb)ed the other one ... ? Point!" or "Which one (verb)ed ... Point!” In contrast we used a plural noun (e.g., the animals) and two scenes containing two participants and asked the children to point to the scene which best matched the simple intransitive.

By introducing a plural noun we introduced a conflict between the number of nouns and the number of participants in the simple intransitive. While the 
simple intransitive contained only one noun (the animals), this noun was marked with plural morphology and the sentence also included a plural auxiliary. On the basis of the number of nouns cue alone, the presence of one noun should have indicated that there was one semantic role and hence led the child to assume the structure referred to an event with one semantic role (i.e., the non-causal event). However, the presence of the plural morphology on the noun and the plural auxiliary indicated that there were two participants, and therefore that the simple intransitive could equally well refer to an event with two semantic roles (i.e., the causal event).

It is interesting to note that while the adults were close to ceiling performance on all sentence types, they did not perform consistently and pick the non-causal scene in $100 \%$ of the trials. While this finding may be surprising given the simplicity of the syntax presented, it is likely to stem from the fact that both simple and conjoined agent intransitives are not necessarily non-causal but can also be used to refer to causal events such as 'playing' and 'fighting'. On this basis, to associate the conjoined agent intransitive with the non-causal scene the participant has to infer which of the two possible options provides the better match to the sentence. Adults may be more successful at this task because they have a stronger knowledge of form-function mappings and are more sensitive to the pragmatic cues of the experiment. They are likely to assume that in the context of a forced-choice task, only one response is 'correct', and to infer that as the primary difference between the scenes relates to causality; if the speaker had wanted to describe the causal scene they would have used the transitive structure. However, the fact that the intransitive sentence could conceivably be used to refer to a causal scene may have caused the adults to choose the causal scene as a match occasionally.

A similar explanation may also account in part for the children's performance on the simple intransitive sentences. Although single noun intransitives are syntactically simple, they can be used in certain contexts to refer to causal actions. Whereas the adults were able to disregard a causal interpretation, presumably by inferring that the sentences with only one noun mapping to one semantic role provided a better match to the non-causal scene, the children were less able to do so. These sentences may be particularly difficult for the children because they are broadly compatible with both scenes; the use of a single pronoun gives minimal information about the relation between participants, and children may be less adept at inferring that, had the speaker wished to describe a causal scene, they would have used a sentence containing two distinct semantic roles. This conflict between cues may have made the simple intransitive sentences particularly confusing and thus led to chance performance. 
The results of Study I suggest that, at three years of age, children are still developing a full understanding of sentence structure. On the one hand, previous studies suggest that children of this age have a fairly solid grasp of the simple transitive construction (Arunachalam \& Waxman, 2010; Naigles, I990; Noble et al., 20I I). On the other hand, our results (and others) suggest that children of this age are still prepared to accept conjoined agent intransitives as descriptions of a causal scene, although this appears to be influenced by the extent to which the linguistic description maps on to a typical transitive (i.e., by having the first noun refer to the causal agent). Consequently, the question facing the field is, what are children sensitive to in the input which enables them to develop a more accurate and robust representation of both the simple transitive and conjoined agent intransitive structures, such that conflicting cues no longer cause them to interpret sentences in a non-adultlike way? In the real world there are likely to be many more cues to meaning than those present in Study I. One major cue to sentence interpretation is the animacy of the noun referents, and it is this cue and its interaction with transitivity and causality that we focus on in Study 2.

\section{STUDY 2}

A number of studies have indicated that children are sensitive to animacy as a cue to sentence interpretation, and that particular animacy configurations make structures easier to comprehend. Koff, Kramer, and Fowles (r980) reported that when acting out sentences containing known nouns and verbs, preschool children had more difficulty with sentences containing two animate entities (e.g., The brown cow jumps on the white cow), than sentences with one animate and one inanimate entity (e.g., The girl pushes the table). Corrigan ( 1988 ) reported a similar finding, that regardless of the animacy of the object, children aged two to four years were better able to locate the actor in a transitive sentence if it was an animate rather than an inanimate entity.

Animacy, of course, does not act alone, and Childers and Echols (2004) investigated how children use animacy information in conjunction with syntactic cues. Two-year-olds were presented with visual scenes containing two novel entities engaged in a causal action (e.g., one entity pulled the other by its arm). The NOvEL entities were manipulated for animacy (animate vs. inanimate), and matched to either the agent or patient role. These visual scenes were accompanied by either an agent sentence (e.g., The danu is touching it) or a patient sentence (e.g., It is touching the danu). Children had to infer the referent of the novel word and locate it in the visual scene. If children solely attended to word order, the first named (pro)noun should be interpreted as the agent of the action, regardless of its 
animacy. However, when animacy did not differentiate the two entities (i.e., animate-animate and inanimate-inanimate), performance was at chance. In contrast, when presented with a prototypical causal event in which an animate agent acted on an inanimate patient, the children were able to use their knowledge of word order to correctly identify the danu as the animate entity in the agent sentence condition and the inanimate entity in the patient sentence condition. This suggests that the prototypical causal scene in which an animate entity acts on an inanimate entity has a privileged status with respect to children's comprehension of word order in the transitive causal structure.

Chan et al. (2009) also investigated the relative strength of structural and animacy cues in children's interpretation of the transitive construction using novel verbs, but with Cantonese, German, and English children aged 2;6, $3 ; 6$, and $4 ; 6$. When children were presented with a transitive sentence in which the animacy cue conflicted with the prototypical structural meaning (a sentence containing an inanimate agent and animate patient, e.g., The present tams the chicken), none of the two-year-olds were able to correctly act out the sentence, whereas when the cues converged to indicate the agent of the action (a sentence containing an animate agent and inanimate patient, e.g., the horse tams the telephone) all groups were above chance in their performance. By three years of age, all of the language groups were able to disregard the animacy cue in favour of the structural cue to meaning. These findings suggest that children find sentences with converging cues easier to interpret than sentences with conflicting cues, consistent with the coalition-as-prototypes idea, where cues such as word order and animacy converge (Bates \& MacWhinney, I987).

In Study 2 we investigated the role of animacy in the interpretation of conjoined agent intransitives. As in Study I, children were presented with a causal and a non-causal scene which was accompanied by a conjoined agent intransitive. In this study, only sentences in which the first named noun was the agent in the causal scene were used (agent-conflict sentences in Study I). We tested three-year-old children as this age group displayed inconsistent knowledge of the conjoined agent intransitive structure with these types of sentences in Study $\mathrm{I}$, and thus there was scope for performance to be aided by an animacy cue. The animacy of the entities in the conjoined agent was manipulated. Children were presented with sentences in which both entities were animate $(A N-A N$, e.g., The bunny and the duck are glorping, as in Study I), the first named entity was animate and the second inanimate $(A N-I N$, e.g., The bunny and the ball are glorping), and the first named noun was inanimate and the second animate ( $I N-A N$, e.g., The ball and the bunny are glorping).

We assumed that due to the lack of exposure to the conjoined agent intransitive, children are unlikely to have any well-formed expectations 
about the typical animacy of the agent in conjoined agent intransitives. However, by three years of age they will have expectations about the typical animacy configurations of simple intransitives and transitives, which may aid their interpretation of the conjoined agent intransitive. Previous research has suggested that in the English transitive, children most frequently hear and produce sentences with an animate subject and an inanimate object from the earliest stages of development (Theakston et al., 2012). In contrast, intransitives, typically associated with non-causal scenes, contain a higher proportion of inanimate subject arguments than simple transitive sentences, a pattern that holds cross-linguistically (e.g., Clancy, 2003; DuBois I987). Thus, the animacy configuration of the nouns may provide a strong cue to sentence interpretation which, together with other cues to meaning present in the sentence, can be used to infer the meaning of the structure.

As the role of animacy in the interpretation of conjoined agent intransitives is largely untested, we have used previous corpus work and experimental work on other constructions to make a number of observations about the possible role of animacy in the interpretation of the conjoined agent intransitive. Table I summarises potential cues children may use to interpret the conjoined agent intransitives tested in Study 2.

First, it is possible that conjoined agent intransitives containing either a first or second inanimate noun prior to the verb are more likely to cue a non-causal meaning than sentences containing two animate nouns. This is based on the findings that intransitives contain a higher proportion of inanimate subject arguments than transitives, and are typically associated with non-causal scenes (Clancy, 2003; DuBois I987).

Second, it is possible that a conjoined agent intransitive with an animateinanimate noun configuration will cue a causal interpretation. This is based on the finding that early in development $88.9 \%$ of transitives in the input have an animate-inanimate animacy configuration (Theakston et al., 2012), and thus this animacy configuration may be a strong cue for a causal interpretation. This cue may then compete with the preverbal inanimate noun cue which pulls for a non-causal interpretation.

Third, it is possible, that the AN-IN noun animacy patterning will also cause activation of the causal NVN sentence structure with which it is typically associated in terms of the properties of the related subject and object slots (e.g., Theakston, Ibbotson, Freudenthal, Lieven, \& Tomasello, in press). In this case, the direct mismatch between the word order of the sentence heard $\mathrm{N}(\mathrm{AN})-\mathrm{N}(\mathrm{IN})-\mathrm{V}$ and the word order typically associated with this configuration of animate and inanimate nouns when used to refer to a causal scene, $\mathrm{N}(\mathrm{AN})-\mathrm{V}-\mathrm{N}(\mathrm{IN})$, may facilitate a correct non-causal interpretation. Obviously this weighting of cues is assumed to be implicit, but explicitly as an illustration we could conceptualize this as something 
along the lines of "If I was describing this causal scene, I'd say N(AN)-V-N (IN). I heard $\mathrm{N}(\mathrm{AN})-\mathrm{N}(\mathrm{IN})-\mathrm{V}$, so I'll assume the sentence doesn't refer to the causal scene".

Finally, a conjoined agent intransitive with an animate-animate noun configuration may cue a causal interpretation. This is based on the finding that $95 \%$ of transitives early in development have an animate subject (Theakston et al., 2012). However, the much lower frequency of AN-AN transitives in the input $(6 \cdot 1 \%)$, coupled with the low frequency of conjoined agent intransitives in the input, means that the presence of two animate nouns may not be specifically associated with either structure, thus providing a less reliable cue to meaning.

METHOD

\section{Participants}

Twenty-four three-year-olds $(M=3 ; 4$, range $=3 ; 0-3 ;$ I 0$)$ and eighteen adults $(M=36 ; \mathrm{I} 0$, range $=20 ; 6-66 ; \mathrm{I})$ participated in a language comprehension task using the forced choice pointing method. All were native speakers of British English who had no language difficulties. A further seven children were excluded due to failure to pass the screening trials (4), failure to complete the task (2), and a side bias (I).

\section{Design}

There was one independent variable: animacy of conjoined agent within-subjects with three levels (animate-animate, animate-inanimate, inanimate-animate). In the test trials the non-causal synchronous action scene was always the matching scene and the dependent variable was the proportion of points to the matching non-causal scene.

\section{Counterbalancing}

All four sentences of a given type (AN-AN, AN-IN, IN-AN) were presented together in a single block. The order of the trials within each block was randomized. The order of the testing blocks was fully counterbalanced and the target side was balanced within each sentence type.

\section{Materials}

Visual stimuli. The visual stimuli were created and presented in exactly the same way as in Study I. The movies consisted of combinations of cartoon animations of ducks, rabbits, and balls. In all test trials one scene showed a causal action (e.g., AN-IN, a duck acting on a ball) and the other scene showed a non-causal scene (e.g., AN-IN, both the duck and the ball 
TABLE 4. Mean number of points to the non-causal scene (SD) for each intransitive sentence type for three-year-olds and adults

\begin{tabular}{lll}
\hline & $3 ; 4$ & Adults \\
\hline AN-AN intransitive (4 trials) & $\mathrm{I} \cdot 88(0 \cdot 99)$ & $3 \cdot 22(\mathrm{I} \cdot 22)$ \\
AN-IN intransitive (4 trials) & $3 \cdot \mathrm{I} 7(0.92)$ & $3 \cdot 56(0 \cdot 92)$ \\
IN-AN intransitive (4 trials) & $2 \cdot 67(0.76)$ & $3 \cdot 28(\mathrm{I} \cdot \mathrm{I} 3)$ \\
\hline
\end{tabular}

performing the same actions independently). (See 'Appendix' for details of the twelve novel action pairs and associated novel verbs.)

Audio stimuli. The sentences were recorded and delivered in exactly the same way as in Study I. The same twelve novel verbs were used, but accompanied different actions. As in the agent-conflict trials of Study I, in all test trials the first named noun was the causal agent in the causal scene.

Visual preferences. As in Study I, an additional group of three-year-olds took part in a screening test to determine whether there were any visual preferences for either the causal or non-causal scene in the absence of informative linguistic input. The procedure was identical to that in Study I. A one-sample $t$-test was run with the mean rate of pointing to the non-causal scene as the dependent variable (i.e., the matching scene in the test condition) and chance set at 50\% (6/12 trials). The children did not differ from chance in their selection of the causal vs. non-causal visual scene for the actions used in Study 2 when presented with no informative linguistic input $\left(M=5 \cdot 54, S D=\mathrm{I} \cdot 59 ; t(23)=-\mathrm{I} \cdot 4 \mathrm{I}, p=\cdot \mathrm{I}_{7} \mathrm{I}, d=0.59\right)$.

\section{Procedure and coding}

The procedure and coding was exactly the same as for Study I. Inter-rater reliability was $100 \%$.

\section{RESULTS}

The first analysis checked whether adults associated the three intransitive sentence types with the non-causal scene. Table 4 shows the mean number of points to the non-causal scene for each sentence type. The adults were close to ceiling on all sentence types. A one-sample $t$-test was run for each sentence type, with the mean number of points to the non-causal scene as the dependent variable and chance set at $50 \%(2 / 4)$.

The results showed that adults pointed to the non-causal scene significantly more often than expected by chance for all three intransitive sentence types (AN-AN sentences: $M=3 \cdot 22, S D=\mathrm{I} \cdot 22, \quad t(\mathrm{I} 7)=4 \cdot 27$, $p=.00 \mathrm{I}, d=2.07$; AN-IN sentences: $M=3.56, S D=0.92, t(\mathrm{I} 7)=7 \cdot \mathrm{I} 6$, $p=.00 \mathrm{I}, d=3.47$; IN-AN sentences: $M=3.28, S D=\mathrm{I} \cdot \mathrm{I} 3, t(\mathrm{I} 7)=4.8 \mathrm{I}$, 
$p=.00 \mathrm{I}, d=2 \cdot 33)$. This confirms that, for the adults, the non-causal scene was an appropriate match for the linguistic audio.

The second analysis examined performance on the real verb practice trials in order to check that the children were able to complete the simple pointing task. A one-sample $t$-test with chance set at I (50\% of 2 trials) was run. The results confirmed that the children were pointing to the matching scene significantly more than would be expected by chance $(M=\mathrm{I} \cdot 92$, $S D=0.28, t(23)=\mathrm{I} 5.9 \mathrm{I}, p=.00 \mathrm{I}, d=6.63)$, indicating that children were able to follow the audio to find the matching scene and therefore understood the requirements of the pointing task.

The third analysis investigated performance on the three sentence types (AN-AN, AN-IN, and IN-AN). A one-way repeated-measures ANOVA was run with sentence type (AN-AN vs. AN-IN vs. IN-AN) as the independent variable, and mean rate of pointing to the non-causal scene as the dependent variable. There was a main effect of sentence type $(F(2,46)=$ I $5.80, p=.0 \mathrm{I}$, partial eta squared $=\cdot 4 \mathrm{I})$. Post-hoc comparisons revealed that the children performed significantly better on AN-IN sentences $\left(M=3 \cdot I_{7}, S E=\cdot I_{9}, p=.00 \mathrm{I}\right)$ and IN-AN sentences $(M=2 \cdot 67$, $\left.S E=\cdot_{1} 6, p=\cdot 003\right)$ than AN-AN sentences $\left(M={ }_{\mathrm{I}} \cdot 88, S E=\cdot 20\right)$. Children also performed significantly better on AN-IN sentences than IN-AN sentences $(p=$. OI I $)$

The fourth analysis investigated whether performance on each sentence type was significantly different to chance. To allow comparison with the adult participants, Table 4 shows the mean rate of pointing to the non-causal scene for each sentence type. A one-sample $t$-test was run with the mean number of points to the non-causal scene as the dependent variable and chance set at 50\% ( 2 of 4 trials), with $p$ values adjusted using the Benjamini-Hochberg method for multiple comparisons. In the AN-AN sentences children did not point to the non-causal scene significantly more than chance $\left(M={ }_{\mathrm{r}} \cdot 88, S D=0.99, t(23)=-0.62, p=.54\right.$, $d=0.26$ ). In both the AN-IN and the IN-AN sentences children pointed to the non-causal scene significantly more than chance (AN-IN: $M=3 \cdot 17$, $S D=0.92, t(23)=6.23, p=.00 \mathrm{I}_{5}, d=2.60 ;$ IN-AN: $M=2.67, S D=0.76$, $\left.t(23)=4 \cdot 29, p=\cdot 00 \mathrm{I}_{5}, d=\mathrm{I}_{\mathrm{I}} \cdot 79\right)$.

\section{DISCUSSION}

In Study 2 we expanded the range of surface cues available for the assignment of meaning to the conjoined agent intransitive structure by investigating whether the animacy of the two nouns in the conjoined agent affects children's interpretation of the structure. We hypothesized that, given the lack of exposure to the conjoined agent intransitive, children would have poorly defined expectations relating to the animacy of 
participants in this particular structure. We expected, however, that children would have knowledge of the typical animacy of agents (and patients) in other frequent constructions in their input, i.e., simple intransitives and transitives.

Children age three associated conjoined agent intransitives with a non-causal scene when the conjoined agent contained an animacy contrast (IN-AN or AN-IN). There was also a significant difference in performance on the conjoined agent intransitives containing an animacy contrast. Children associated the AN-IN conjoined agent intransitives with a noncausal scene significantly more often than the IN-AN conjoined agent intransitives. As in Study I, children aged three did not associate an agent-conflict conjoined agent intransitive with a non-causal scene when both entities in the conjoined agent were animate (AN-AN). Given the failure to associate the AN-AN intransitive with the non-causal scene, the results indicate that the addition of an animacy contrast allows the child to draw on grammatical knowledge they have associated with animate and inanimate entities, which pulls for a non-causal interpretation of the conjoined agent intransitive. We now explore these findings with reference to the animacy cues we outlined in the 'Introduction'.

There are two animacy cues which pull for a causal interpretation in the AN-IN conjoined agent intransitive. First, the animacy configuration matches the prototypical animacy configuration of the transitive structure (Theakston et al., 2012), and second, the first noun is animate, which is more frequent for the transitive structure than the intransitive (Clancy, 2003; DuBois I987). As both of these animacy cues pull for a causal interpretation, it might be expected that the children would associate the AN-IN conjoined agent intransitive with a causal scene. However, when we consider the role of word-order cues this seems less likely. Based on input statistics, it is clear that young children are highly familiar with transitives with an AN-IN animacy configuration and consequently may expect to hear transitive word order with this animacy configuration. Therefore, hearing the mismatch between the animacy cues and word order cues in the AN-IN conjoined agent intransitive may lead them to reject the causal scene and pick the non-causal alternative.

In contrast, the animacy cues present in the IN-AN conjoined agent intransitive do not pull for the causal scene. First, the presence of an inanimate noun in first position is more frequent in intransitive structures which are typically associated with non-causal scenes (Clancy, 2003; DuBois I987). Second, the IN-AN animacy configuration is the least frequent transitive animacy configuration in the input (0.19\%; Theakston et al,. 2012) and thus is unlikely to cue causal scene selection. On this basis it appears that an inanimate noun in first position is a strong cue for a non-causal interpretation. 
Finally, the lack of association between the AN-AN sentence and the non-causal scene may indicate that when animacy is neutralized the mismatch between the conjoined agent intransitive and transitive word order is not sufficient for the children to reject the causal scene. The low frequency of AN-AN transitives in the input (6.1\%; Theakston et al., 20I2) coupled with the low frequency of conjoined agent intransitives in the input may mean that the presence of two animate nouns is not specifically associated with either structure, thus providing a less reliable cue to meaning. A previous study by Koff et al. (1980) found that children were less able to comprehend and act out transitive sentences with two animate participants than transitive sentences with one animate and one inanimate participant. Perhaps animate-animate structures are more challenging due to the low frequency of such animacy configurations in the input.

In summary, it is clear from our findings that the degree to which children aged three are prepared to accept a conjoined agent intransitive as a description of a non-causal scene is influenced by the animacy of the entities in the conjoined agent and the degree to which they map onto the typical form-function mappings associated with causal and non-causal scenes. This is in line with previous findings that the animacy of participants influences children's interpretations of the simple transitive structure (e.g., Chan et al., 2009; Childers \& Echols, 2004; Corrigan, I 988; Koff et al., I980), suggesting that typical form-function mappings are an important source of information used by children when interpreting sentence structure (see also Brandt, Kidd, Lieven, \& Tomasello, 2009, for the role of animacy in interpreting object relatives).

\section{GENERAL DISCUSSION}

In this paper we report the results of two studies designed to investigate what kind of knowledge underlies children's ability to interpret the conjoined agent intransitive structure. Table I provides a summary of the cues we investigated and the children's results.

In Study I, we compared children's performance on conjoined agent intransitives as a function of whether the first noun in the conjoined agent was or was not also the agent in the causal scene. Both nouns in the conjoined agent were animate. The results indicated that only four-yearolds showed robust comprehension of the conjoined agent intransitive and were able to successfully interpret both kinds of intransitive sentences. In contrast, the three-year-olds were influenced by the specific pattern of the nouns. When the first noun in a conjoined agent intransitive sentence matched the agent in the causal scene, children did NOT point to the non-causal scene significantly more than would be expected by chance.

$$
836
$$


However, the same children did associate the conjoined agent intransitive with the non-causal scene when the first noun was not the agent in the causal scene (but instead referred to the patient).

In addition, we examined whether replacing the conjoined agent with a single plural noun (e.g., the animals are glorping) in a simple intransitive in which the number of nouns and the number of semantic roles were aligned improved children's comprehension. None of the children associated this intransitive structure with the non-causal scene.

In Study 2, we compared children's performance on conjoined agent intransitives as a function of the animacy of the two nouns in the conjoined agent. The results indicated that children's comprehension was influenced by the animacy of these two nouns. Children associated the conjoined agent intransitive with the non-causal scene in the IN-AN and AN-IN intransitives but not the AN-AN intransitive. We propose that this pattern of results is due to the children's knowledge of the typical animacy of other frequent structures in their input, namely transitives and simple intransitives.

Taken together, the results from these studies provide evidence that children's syntactic knowledge is not fully adultlike early in development, but rather is supported by salient cues in the sentence structure, which allow children to correctly assign meaning to some but not all structures. The pattern of results indicates that children are processing a number of different cues when inferring the meaning of the conjoined agent intransitive. These cues appear to be in competition with each other and the cue or cues that receive the most activation are used to infer the meaning of the construction.

These findings are consistent with usage-based approaches and indicate that children's knowledge of syntactic structures forms a network of organization, such that knowledge of prototypical instantiations of a structure can impact on interpretation of not only that structure but also others. For example, the influence of a first-noun-as-causal-agent cue is mediated by the animacy properties of other participants, the sentence structure in which they appear, and already learned form-function mappings for other sentence structures. Alternative accounts, which posit innate semantic representations and some learning of syntax (e.g., syntactic bootstrapping), may also be consistent with the pattern of data. However, these accounts make different claims about the origins of the child's sensitivity to these cues. For example, the structure mapping account of the origins of syntactic bootstrapping suggests that "children begin with an unlearned bias towards one to one mapping between number of nouns in a sentence and the participant roles in an event" (Gertner \& Fisher, 2012 , p. 85). In addition, according to such accounts, children are assumed to be biased towards sentence representations which allow 
Video
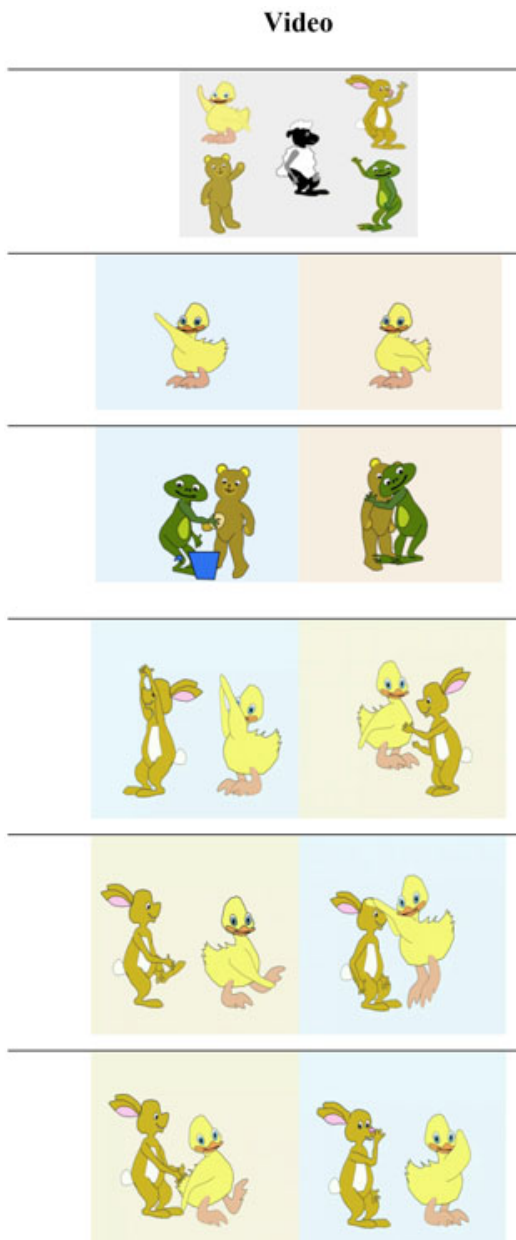

Test trial - number of nouns

"The animals are daxing! Point to

where the animals are daxing!"

Fig. I. Example scenes.

linguistic generalizations (e.g., noun and agent). In contrast, usage-based accounts posit that children become sensitive to various cues to meaning due to properties of the input. For example, the frequency of the animacy configuration of the prototypical transitive in the input appears to influence the interpretation of the conjoined agent intransitive.

In summary, the current studies contribute to understanding of how children's knowledge of sentence structure changes over the course of development. The complexity of the learning context, once even just some of the cues available to children are taken into consideration, demonstrates 
that in order to understand the nature of children's linguistic representations, we need a full understanding of how cues interact at different stages in development, and how sentence structures are represented in relation to one another. Thus, the critical questions concern not when in development children are able to understand a particular structure, but rather the basis of this knowledge and how it develops over time, given the child's language environment and their knowledge of other, related structures.

\section{REFERENCES}

Abbot-Smith, K., \& Behrens, H. (2006). How known constructions influences the acquisition of other constructions: the German passive and future constructions. Cognitive Science 3o, 995-1026.

Ambridge, B., Kidd, E. J., Rowland, C. F., \& Theakston, A. L. (2015). The ubiquity of frequency effects in first language acquisition. Fournal of Child Language 42(2), 239-73.

Arunachalam, S., \& Waxman, S. R. (2010). Meaning from syntax: evidence from 2-year-olds. Cognition II4, 442-6.

Barner, D., Thalwitz, D., Wood, J., \& Carey, S. (2007). On the relation between the acquisition of singular-plural morpho-syntax and the conceptual distinction between one and more than one. Developmental Science ro, ${ }_{36}^{6}-73$.

Bates, E., \& MacWhinney, B. (1987). Competition, variation, and language learning. In B. MacWhinney (Ed.), Mechanisms of language acquisition (pp. I 57-193). Hillsdale, NJ: Erlbaum.

Bever, T. G. (I970). The cognitive basis for linguistic structure. In J. R. Hayes (Ed.), Cognition and the development of language (pp. 279-362). New York: Wiley.

Brandt, S., Kidd, E., Lieven, E. V. M., \& Tomasello, M. (2009). The discourse bases of relativization: an investigation of young German- and English-speaking children's comprehension of relative clauses. Cognitive Linguistics 20, 539-70.

Cameron-Faulkner, T., Lieven, E. V. M., \& Tomasello, M. (2003). A construction based analysis of child directed speech. Cognitive Science 27, 843-73.

Candan, A. E., Küntay, A. C., Yeh, Y., Cheung, H., Wagner, L., \& Naigles, L. R. (2012). Language and age effects in children's processing of word order. Cognitive Development 27, 205-2I.

Chan, A., Lieven, E. V. M., \& Tomasello, M. (2009). Children's understanding of the agentpatient relations in the transitive construction: cross-linguistic comparisons between Cantonese, German and English. Cognitive Linguistics 20, 267-300.

Chang, F., Dell, G. S., \& Bock, K. (2006). Becoming syntactic. Psychological Review Ir3, $243-72$.

Childers, J. B., \& Echols, C. H. (2004). 21/2-year-old children use animacy and syntax to learn a new noun. Infancy 5, 109-25.

Clancy, P. M. (2003). The lexicon in interaction: developmental origins of preferred argument structure in Korean. In J. W. Du Bois, L. Kumpf, \& W. Ashby (Eds), Preferred argument structure: grammar as architecture for function (pp. 8I-108). Amsterdam: John Benjamins.

Clark, E. V., \& Nikitina, T. (2009). One vs. more than one: antecedents to plurality in early language acquisition. Linguistics 47, г $03-39$.

Corrigan, R. (I 988 ). Who dun it? The influence of actor-patient animacy and type of verb in the making of causal attributions. Fournal of Memory and Language 27, 447-65.

Dittmar, M., Abbot-Smith, K., Lieven, E., \& Tomasello, M. (2008) German children's comprehension of word order and case marking in causative sentences. Child Development 79, i I $52-67$.

Du Bois, J. W. (I987). The discourse basis of ergativity. Language 63, 805-55. 
Ferreira, F. (2003). The misinterpretation of noncanonical sentences. Cognitive Psychology 47, I64-203.

Fisher, C. (1994). Structure and meaning in the verb lexicon: input for a syntax-aided verb learning procedure. Language and Cognitive Processes 9, 473-5 I 8 .

Fisher, C. (1996). Structural limits on verb mapping: the role of analogy in children's interpretations of sentences. Cognitive Psychology 3I, 4I-8I.

Fisher, C. (2002). Structural limits on verb mapping: the role of abstract structure in 2.5-year-olds' interpretations of novel verbs. Developmental Science 5, 55-64.

Gertner, Y., \& Fisher, C. (2012). Predicted errors in children's early sentence comprehension. Cognition 124, 85-94.

Gertner, Y., Fisher, C., \& Eisengart, J. (2006). Learning words and rules: abstract knowledge of word order in early sentence comprehension. Psychological Science r7, 684-9I .

Hirsh-Pasek, K., Golinkoff, R., \& Naigles, L. ( I 996). Young children's use of syntactic frames to derive meaning. In K. Hirsh-Pasek \& R. Golinkoff (Eds), The origins of grammar: evidence from early language comprehension ( $\mathrm{pp}$. I23-1 58). Cambridge, MA: MIT Press.

Ibbotson, P., Theakston, A. L., Lieven, E. V. M., \& Tomasello, M. (20I I). The role of pronoun frames in early comprehension of transitive constructions in English. Language Learning and Development 7, I-I 6 .

Kidd, E., Bavin, E. L., \& Rhodes, B. (200I). Two-year-olds' knowledge of verbs and argument structures. In M. Almgren, A. Barren, M.-J. Ezeiz-abarrena, I. Idiazabal, \& B. MacWhinney (Eds), Research on child language acquisition: proceedings of the 8th conference of the International Association for the Study of Child Language (pp. I368I 382 ). Somerville, MA: Cascadilla Press.

Koff, E., Kramer, P. E., \& Fowles, B. (1980). Effects of event probability and animateness on children's comprehension of active and passive sentences. Fournal of Psychology ro4, I $57-63$.

Kouider, S., Halberda, J., Wood, J., \& Carey, S. (2006). Acquisition of English number marking: the singular-plural distinction. Language Learning and Development 2, I-25.

Krajewski, G., and Lieven, E. V. M. (20I4). Competing cues in early syntactic development. In B. MacWhinney, A. Malchukov, \& E. A Moravcsik (Eds), Competing motivations in grammar and usage (pp. I63-I77). Oxford: Oxford University Press.

Lemetyinen, H., Theakston, A. L., \& Lieven, E. V. M (in prep.). How do Finnish children comprehend word order and case marking cues in transitive sentences with novel verbs? Manuscript in preparation.

Lidz, J., Gleitman, H., \& Gleitman, L. (2003). Understanding how input matters: verb learning and the footprint of universal grammar. Cognition 87, I 5 I-78.

MacWhinney, B., Pleh, C., \& Bates, E. ( $9_{9} 8_{5}$ ). The development of sentence interpretation in Hungarian. Cognitive Psychology r7, I78-209.

Maratsos, M. P. (I 974). Children who get worse at understanding the passive: a replication of Bever. Fournal of Psycholinguistic Research 3, 65-74.

Naigles, L. ( I 990). Children use syntax to learn verb meanings. Fournal of Child Language I7, 357-74.

Naigles, L., \& Kako, E. (I993). First contact in verb acquisition: defining a role for syntax. Child Development 64, i665-87.

Noble, C. H., Rowland, C. F., \& Pine, J. M. (20I I). Comprehension of argument structure and semantic roles: evidence from English-learning children and the forced-choice pointing paradigm. Cognitive Science 35, 963-82.

O’Shannessy, C. (2010). Competition between word order and case-marking in interpreting grammatical relations: a case study in multilingual acquisition. Fournal of Child Language 38, 763-92.

Rowland, C. F., \& Noble, C. H. (201I). The role of syntactic structure in children's sentence comprehension: evidence from the dative. Language Learning and Development 7, $55-75$.

Slobin, D. I. ( 1 966). Grammatical transformations and sentence comprehension in childhood and adulthood. Fournal of Verbal Learning and Verbal Behavior 5, 219-27. 
Theakston, A. L, Ibbotson, P., Freudenthal, D., Lieven, E. V. M, \& Tomasello, M. (in press). Productivity of noun slots in verb frames. Cognitive Science.

Theakston, A. L., Maslen, R., Lieven, E. V. M., \& Tomasello, M. (2012). The acquisition of the active transitive construction in English: a detailed case study. Cognitive Linguistics 23, $9 \mathrm{I}-\mathrm{I} 28$.

Wood, J., Kouider, S., \& Carey, S. (2009). Acquisition of singular-plural morphology. Developmental Psychology 45, 202-6.

Yuan, S., \& Fisher, C. (2009). 'Really? She blicked the baby': two-year olds learn combinatorial facts about verbs by listening. Psychological Science 2o, 619-26.

\section{APPENDIX}

TABLE I. Descriptions of the target and foil actions for the test stimuli and associated novel verbs in Study I

\begin{tabular}{|c|c|c|}
\hline & Causal scene & Non-causal scene \\
\hline Blick & $\begin{array}{l}\text { The duck bangs into the bunny and } \\
\text { makes the bunny bend backwards. }\end{array}$ & $\begin{array}{l}\text { The bunny and the duck squat and push } \\
\text { their arms out behind them. }\end{array}$ \\
\hline Dax & $\begin{array}{l}\text { The bunny pushes down on the duck's } \\
\text { tail and makes the duck move } \\
\text { backwards. }\end{array}$ & $\begin{array}{l}\text { The duck and the bunny cover one of } \\
\text { their eyes with their arm. }\end{array}$ \\
\hline Glorp & $\begin{array}{l}\text { The duck moves the bunny's head } \\
\text { backwards and then pushes the bunny } \\
\text { forwards by his head. }\end{array}$ & $\begin{array}{l}\text { The duck and the bunny swing one of } \\
\text { their arms back and forth whilst } \\
\text { nodding their heads. }\end{array}$ \\
\hline Filp & $\begin{array}{l}\text { The duck pulls the bunny's shoulder and } \\
\text { makes the bunny bend backwards. }\end{array}$ & $\begin{array}{l}\text { The bunny and the duck swing one of } \\
\text { their legs back and forth. }\end{array}$ \\
\hline $\operatorname{Rax}$ & $\begin{array}{l}\text { The bunny takes the duck's hand and } \\
\text { pushes it upwards. }\end{array}$ & $\begin{array}{l}\text { The duck and the bunny perform the } \\
\text { splits. }\end{array}$ \\
\hline Wug & $\begin{array}{l}\text { The bunny pushes the duck on the } \\
\text { bottom and makes the duck tip forward. }\end{array}$ & $\begin{array}{l}\text { The bunny and the duck circle their arms } \\
\text { in the air like a windmill. }\end{array}$ \\
\hline Krad & $\begin{array}{l}\text { The bunny lifts the duck into the air and } \\
\text { places the duck back onto the ground. }\end{array}$ & $\begin{array}{l}\text { The duck and the bunny raise their arms } \\
\text { in the air and clap their hands above } \\
\text { their heads. }\end{array}$ \\
\hline Pilk & $\begin{array}{l}\text { The bunny lifts the duck's foot and } \\
\text { makes the duck move backwards. }\end{array}$ & $\begin{array}{l}\text { The bunny and the duck raise one knee in } \\
\text { the air and pull arms downwards. }\end{array}$ \\
\hline Jemm & $\begin{array}{l}\text { The duck pushes down on the bunny's } \\
\text { head and makes the bunny go into a } \\
\text { squat position. }\end{array}$ & $\begin{array}{l}\text { The duck and the bunny raise one foot in } \\
\text { the air and touch it with one hand. }\end{array}$ \\
\hline Meek & $\begin{array}{l}\text { The duck pushes down on the bunny's } \\
\text { knee and makes the bunny squat } \\
\text { downwards. }\end{array}$ & $\begin{array}{l}\text { The bunny and the duck bend backwards } \\
\text { and raise their arms in the air. }\end{array}$ \\
\hline Rick & $\begin{array}{l}\text { The duck reaches up and moves the } \\
\text { bunny's head and neck backwards. }\end{array}$ & $\begin{array}{l}\text { The bunny and the duck swing one of } \\
\text { their arms in a full circle. }\end{array}$ \\
\hline Grad & $\begin{array}{l}\text { The bunny takes the ducks arms and } \\
\text { pulls the duck backwards. }\end{array}$ & $\begin{array}{l}\text { The duck and the bunny raise one arm } \\
\text { into the air and flex it up and down. }\end{array}$ \\
\hline
\end{tabular}


TABLE 2. Descriptions of the target and foil actions for the test stimuli and associated novel verbs in Study 2

\begin{tabular}{|c|c|c|}
\hline & Causal scene & Non-causal scene \\
\hline $\operatorname{Rax}$ & $\begin{array}{l}\text { The duck pulls the bunny's shoulder and } \\
\text { makes the bunny bend backwards. }\end{array}$ & $\begin{array}{l}\text { The duck and the bunny raise one foot in } \\
\text { the air and touch it with one hand. }\end{array}$ \\
\hline Meek & $\begin{array}{l}\text { The duck pushes down on the bunny's } \\
\text { head and makes the bunny go into a } \\
\text { squat position. }\end{array}$ & $\begin{array}{l}\text { The duck and the bunny raise one arm } \\
\text { into the air and flex it up and down. }\end{array}$ \\
\hline Grad & $\begin{array}{l}\text { The bunny takes the duck's arms and } \\
\text { pulls the duck backwards. }\end{array}$ & $\begin{array}{l}\text { The duck and the bunny cover one of } \\
\text { their eyes with their arm. }\end{array}$ \\
\hline Dax & $\begin{array}{l}\text { The bunny pushes the duck on the } \\
\text { bottom and makes the duck tip forward. }\end{array}$ & $\begin{array}{l}\text { The bunny and the duck swing one of } \\
\text { their legs back and forth. }\end{array}$ \\
\hline Krad & $\begin{array}{l}\text { The duck pushes the ball downwards and } \\
\text { it springs back up into the duck's hand. }\end{array}$ & $\begin{array}{l}\text { The duck and the bunny fall downwards } \\
\text { and tip backwards then move upwards } \\
\text { again. }\end{array}$ \\
\hline Rick & $\begin{array}{l}\text { The } \\
\text { scre }\end{array}$ & $\begin{array}{l}\text { The duck and the ball bounce up and } \\
\text { down. }\end{array}$ \\
\hline Blick & $\begin{array}{l}\text { The bunny lifts the ball and pushes it } \\
\text { upwards; the ball falls down and lands at } \\
\text { bunny's feet. }\end{array}$ & $\begin{array}{l}\text { The bunny and the ball spin } 360^{\circ} \text { around } \\
\text { a fixed point. }\end{array}$ \\
\hline Pilk & The bunny lifts the ball up and down. & $\begin{array}{l}\text { The bunny and ball jump upwards and } \\
\text { do a backwards somersault. }\end{array}$ \\
\hline Filp & $\begin{array}{l}\text { The ball drops down and hits the duck on } \\
\text { the head which squashes the duck } \\
\text { downwards. }\end{array}$ & $\begin{array}{l}\text { The ball and the duck jump across the } \\
\text { screen from right to left. }\end{array}$ \\
\hline Wug & $\begin{array}{l}\text { The ball hits the bunny on the bottom } \\
\text { and pushes him upwards and forwards. }\end{array}$ & $\begin{array}{l}\text { The ball and the bunny shrink into the } \\
\text { distance and get smaller and then come } \\
\text { back to the foreground and get bigger } \\
\text { again. }\end{array}$ \\
\hline Jemm & $\begin{array}{l}\text { The ball hits the bunny in the stomach } \\
\text { and pushes him backwards. }\end{array}$ & $\begin{array}{l}\text { The ball and the bunny rock backwards } \\
\mathrm{I}^{\circ} \mathrm{o}^{\circ} \text { around a fixed point and then } \\
\text { return to the upright position. }\end{array}$ \\
\hline Glorp & $\begin{array}{l}\text { The ball hits the duck on the back of the } \\
\text { head and pushes the duck forwards. }\end{array}$ & $\begin{array}{l}\text { The ball and the duck somersault across } \\
\text { the screen from right to left. }\end{array}$ \\
\hline
\end{tabular}

